\title{
AGENTES ETIOLOGICOS DE LA CANDIDOSIS EN EL NIÑO
}

\author{
ARIEL ARIAS, ${ }^{*}$ ELIZABETH CASTAÑEDA, ${ }^{* *}$ NELLY ORDOÑEZ, *** LIVIA BUSTOS.****
}

\begin{abstract}
Se estudiaron 169 pacientes hospitalizados en el Instituto Materno Infantil de Bogotá con diagnóstico clínico de Candidosis, practicándose examen microscópico directo de sus lesiones con cultivo subsecuente para intentar aislar al microorganismo responsable. Se obtuvieron 137 aislamientos, de los cuales el $89.7 \%$ correspondieron a Candida albicansy el resto a otras especies de los géneros Candida $(2.8 \%)$. Trichosporon $(3.7 \%)$ y Cryptococcus $(0.7 \%)$. Tres aislamientos no pudieron ser tipificados. Entre los factores predisponentes se encontró, en primer término, la enfermedad diarreica aguda con desnutrición, seguida por la deshidratación, la prematurez y el uso de antibióticos.
\end{abstract}

La enfermedad conocida actualmente como candidosis se divide, según el mecanismo fisiopatológico de la lesión, en: enfermedad de tipo infeccioso, la cual es generalmente oportunista y presenta compromiso mucocutáneo, cutáneo únicamente o sistémico y enfermedad de tipo alérgico (1). Ya en 1797 se sabía con exactitud que no existía relación alguna entre el género Candida y el género Monilia (1); sinembargo, el término "Moniliasis" ha persistido a través de los tiempos para describir a todas aquellas entidades en las cuales la Candida albicans u otras especies del género Candida son sus agentes etiológicos. Estas entidades son cada vez de mayor interés dado el aumento de su frecuencia, por el actual potencial quimioterapéutico existente y por la posible patogenicidad de gérmenes que hasta ahora no han sido reconocidos como patógenos (2).

En este trabajo nos referimos a un par de enfermedades de tipo infeccioso mucocutáneo, conocidas como candidosis oral y candidosis alimentaria (3), las cuales afectan principalmente la población infantil por ser el grupo de edad con mayor susceptibilidad a sufrirlas. Revisamos 169 pacientes, lactantes, hospitalizados en el Instituto Materno Infantil (I. M. I.) de Bogotá, cuyo diagnóstico clínico era candidosis, con el fin de identificar a su agente etiológico y establecer la importancia de la identificación de las especies de los géneros aislados.

\footnotetext{
* Estudiante de Medicina. Universidad Nacional. Becario Laboratorio de Micología Médica. Grupo de Microbiología e Inmunología. Instituto Nacional de Salud.

** Microbióloga. M. Sc. Laboratorio de Micología Médica. Grupo de Microbiología e Inmunología. Instituto Nacional de Salud.

*** Bióloga. Laboratorio de Micología Médica. Grupo de Microbiología e Inmunología. Instituto Nacional de Salud.

**** Microbióloga. Laboratorio de Micología Médica. Grupo de Microbiología e Inmunología. Instituto Nacional de Salud.
} 


\section{MATERIALES Y METODOS}

Durante el año comprendido entre octubre de 1979 y octubre de 1980 se revisaron 169 pacientes hospitalizados en el I. M. I. de Bogotá, para lo cual se diseñó un formulario que precisaba: edad y sexo de los pacientes, localización y caracteres de la lesión, diagnóstico, condición de base y tratamiento.

En total se tomaron 172 muestras con escobillón, para examen directo y cultivo.

El examen directo se realizó con la coloración de Gram. El cultivo se hizo de 41 muestras, en cajas de Petri con agar glucosado de Sabouraud, adicionado con antibióticos (Mycosel BBL) y de las 131 restantes, en el medio selectivo para Candida, según Nickerson (Merck).

Los cultivos se incubaron a $27^{\circ} \mathrm{C}$, por 10 días.

Las cepas con una morfología macroscópica característica de levadura se aislaron en agar glucosado de Sabouraud y se siguió el siguiente procedimiento para su identificación (4):

\section{Morfología microscópica.}

2. Visualización del fenómeno de ReynoldsBraude (tubo germinal).

3. Producción de clamidosporas en agar sémola de maíz más Tween 80 .

4. Asimilación de azúcares en el medio de Wickerham modificado (Adams y Cooper (5).

\section{RESULTADOS}

La edad de los pacientes osciló entre los 3 días y los 12 meses; 49 (28.9\%) eran menores de un mes; $94(55.6 \%)$ eran hombres y 75 $(44.3 \%)$ mujeres. En todos se comprobó clínicamente la entidad. Las lesiones membranosas se presentaron en mayor proporción que las otras; siguen, en orden de importancia, las maculoeritematosas y las queratinizadas. Estas lesiones se hallaban en su mayoría en la cavidad oral, (79.5\%);
$17.6 \%$ en la región perianal y $2.9 \%$ en otras localizaciones.

La patología de base más frecuentemente encontrada fue la enfermedad diarreica aguda con desnutrición en el 56.8\% (Tabla 1), seguida por deshidratación en el $49.1 \%$. Solamente 22 pacientes presentaron una única patología de base $(13 \%)$; los demás tenían 2 o más patologías asociadas.

$104(61.54 \%)$ pacientes recibían antibioterapia con o sin nistatina; $57(33.73 \%)$ recibían únicamente nistatina y tan solo 8 $(4.73 \%)$ no recibían antibiótico alguno.

TABLA 1. Patología de base más frecuentemente encontrada en los 169 niños lactantes.

\begin{tabular}{lcr}
\hline & \multicolumn{2}{c}{ Pacientes } \\
\cline { 2 - 3 } Patología de base & No. & 56.8 \\
\hline Enfermedad diarreica aguda & 96 & 56.8 \\
Desnutrición & 96 & 49.1 \\
Deshidratación & 83 & 18.3 \\
Prematurez & 31 & 17.1 \\
Bronconeumonía & 29 & 13.0 \\
Sindrome de dificultad respiratoria & 22 & 8.8 \\
Sepsis & 15 & \\
\hline
\end{tabular}

De las 172 muestras obtenidas en los 169 pacientes se lograron 137 aislamientos $(77.4 \%)$. El mayor número correspondió a especies del género Candida. Se aislaron también especies de los géneros Trichosporon, Torulopsis, Cyptococcus y tres levaduras que no pudieron ser identificadas por los métodos ya descritos, (Tabla 2).

En la Tabla 3 se describen las especies de los géneros Candida, Trichosporon y Cryptococcus aisladas; la más frecuente fue la Candida albicans, en el $89.7 \%$ de los pacientes.

En 5 pacientes se aislaron 2 microorganismos diferentes, los cuales están descritos en la Tabla 4. 
ARIEL ARIAS, ELIZABETH CASTAÑEDA, NELLY ORDOÑEZ, LIVIA BUSTOS

TABLA 2. Identificación por géneros de las 137 especies de levaduras aisladas en niños laciantes.

\begin{tabular}{|c|c|c|}
\hline \multirow{2}{*}{ Género } & \multicolumn{2}{|c|}{ Aislamientos } \\
\hline & No. & $\%$ \\
\hline Candida & 128 & 93.4 \\
\hline Trichosporon & 5 & 3.7 \\
\hline Cryptococcus & 1 & 0.7 \\
\hline Sin identificar & 3 & 2.2 \\
\hline \multicolumn{3}{|c|}{ 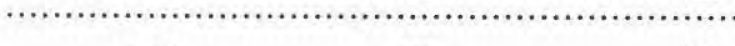 } \\
\hline Total & 137 & 100 \\
\hline
\end{tabular}

TABLA 3, Distribución por especies de los 137 aislamientos.

\begin{tabular}{|c|c|c|}
\hline Especies & No. & $\%$ \\
\hline Candida albicans & 123 & 89.7 \\
\hline C. parapsilosis & 2 & 1.4 \\
\hline C. tropicalis & 2 & 1.4 \\
\hline Trichosporon inkin & 3 & 2.2 \\
\hline T. pullulans & 2 & 1.4 \\
\hline Torulopsis (Candida) glabrata & 1 & 0.7 \\
\hline Cryptococcus uniguttulatus & 1 & 0.7 \\
\hline No tipificados & 3 & 2.2 \\
\hline Total & 137 & 100 \\
\hline
\end{tabular}

De los 164 exámenes directos realizados, 119 fueron positivos $(72.5 \%)$ por observación de levaduras o de levaduras y pseudomicelios; la correlación con los cultivos fue del $89 \%$

\section{DISCUSION}

La candidosis oral es la forma más común de candidosis, siendo el lactante y el neonato las personas más susceptibles a sufrir la enfermedad (3). En el lactante se postula como fenómeno predisponente, la administración de antibióticos que alteran o suprimen la flora bacteriana normal promoviendo el crecimiento de levaduras de tipo Candida.
TABLA 4. Colonización dual por organismos levaduriformes en 5 pacientes pediatricos.

\begin{tabular}{|c|c|}
\hline Paciente (No.) & Microorganismos aislados \\
\hline 1. $(88)$ & $\begin{array}{l}\text { C. tropicalis } \\
\text { C. parapsilosis }\end{array}$ \\
\hline 2. ( $(102)$ & $\begin{array}{l}\text { C. albicans } \\
\text { T. inkin }\end{array}$ \\
\hline
\end{tabular}

3. (113) C. albicans

T. inkin

4. (154) $\frac{\text { C. albicans }}{\text { T. pullulans }}$

5. (172) C. parapsilosis

C. uniguttulatus

Igualmente se señalan condiciones previas del paciente, como la desnutrición, defectos inmunológicos, alteraciones genéticas, enfermedades metabólicas, etc. En el neonato existen, además, otros factores, tales como el pH bajo de la cavidad oral, semejante al de la vagina de las mujeres grávidas $(1,3)$, la ausencia de flora bacteriana y la presencia de vaginitis candidósica en la madre, que facilita la contaminación durante el parto (6).

La candidosis alimentaria es la infección del tracto gastrointestinal, que puede presentarse a cualquier nivel siendo más frecuentes la localización esofágica (como continuación de una forma oral) y la localización perianal. Esta última es muy común en niños, con o sin compromiso intestinal, como complicación o sobreinfección de una piel previamente lesionada por la irritación química que producen la orina y las materias fecales. 
El tipo de patología de base de nuestros pacientes explica fácilmente su susceptibilidad para sufrir la infección y confirma una vez más el papel de gérmen oportunista que juega la Candida. Esto es particularmente importante si tenemos en cuenta el llamado de atención que se hace, en revisiones recientes, acerca del ascenso de las infecciones por Candida hasta un $5^{\circ}$. lugar, en la causalidad de las septicemias nosocomiales (7).

La Candida albicans, considerada la especie más virulenta del género, fue como era de esperarse, la más frecuentemente aislada y en un porcentaje similar al encontrado por otros autores en estudios similares (8). En nuestro medio encontramos dos revisiones hechas en grupos de edad no tan limitados como el nuestro, que señalan porcentajes del $60 \%$ (9) y $60.7 \%$ (10). El aislamiento de otras especies como $C$. tropicalis y C. parapsilosis nos lleva igualmente a plantear como interrogante la importancia de la identificación precisa, sobre todo en aquellos casos de inusitada presentación, en los cuales se describen cada vez mayor número de especies diferentes de la C. albicans $(2,10,11)$.

El hallazgo de especies del género Trichosporon en 5 casos, podría interpretarse, en 3 de ellos, como de organismos saprofitos ya que se aisló como agente a otro patógeno reconocido; sinembargo en los 2 casos restantes se aisló el Tricosporon como agente único. C. uniguttulatus fue hallado, también como agentes saprofito, en un caso. En otro caso se aisló Torulopsis (Candida) glabrata, un oportunista que está cobrando cada vez mayor importancia (12) y del cual no tenemos información en nuestro medio.

Igual que en trabajos anteriores de otros autores (9), podemos decir que el porcentaje de diagnósticos positivos aumenta cuando, además del examen directo, se realiza el cultivo.

Finalmente queremos llamar la atención sobre la alta proporción de pacientes que recibían antibioterapia, incluída la nistatina y su importancia como factor predisponente de la infección.

\section{SUMMARY}

One hundred and sixtynine cases with clinical diagnosis of Candidosis from the Instituto Materno Infantil (Bogotá, Colombia) are reviewed. Direct microscopic examination of material from the lesions and cultures for isolation of the agents were performed. One or more agents were isolated in 137 cases; Candida albicans being present in $89.7 \%$ of the cases; other species of the genus Candida in $2.8 \%$ of them; the genus Trichosporon in $3.7 \%$ and to the genus Cryptococcus $0.7 \%$ of the cases. There were three agents in wich identification was not possible. Acute diarrheic disease, malnutrition, dehydration, premature birth and antibiotic therapy were identified as the most important conditions associated with Candidosis.

\section{AGRADECIMIENTOS}

Agradecemos al Departamento de Pediatría del Instituto Materno Infantil de Bogotá y al doctor Ricardo Alvarado por facilitarnos la realización de este trabajo. Igualmente a la doctora María Taresa Nova y al doctor Camilo Betancourt por su valiosa ayuda en la recolección de las muestras. A la doctora Angela Restrepo y al doctor Mauricio Restrepo por sus comentarios.

\section{BIBLIOGRAFIA}

\footnotetext{
1. Rippon J W. Medical Mycology. Saunders Phil., 1974; pp 177.

2. Ahearn D, Holzchu D. The white yeasts as disease agents: historical perspective, The black and white yeasts, PAHO Scient. Publ. No. 356, 1978; pp $119-123$.

3. Padilha-Goncalves A. Current aspects of mucocutaneous candidiosis. The black and white yeasts. PAHO Scient. Publ. No. 356. 1978; pp $134=140$.

4. Haley L, Callaway C. Laboratory methods in Medical Mycology. H. E. W. Publ. No. $78-8361$ (CDC). pp 111.

5. Adams E D, Cooper B H. Evaluation of modified Wickerham medium for identifying medically important yeasts. Amer. J. Med. Techno. 1974, 40:377.

6. Winner $H$. The epidemiology of candidiasis. The epidemiology of human mycotic diseases. Al = Doory $Y$, (ed) Springfield, 111. Charles C. Thomas; 1975 pp 152-157.
} 


\section{ARIEL ARIAS, ELIZABETH CASTAÑEDA, NELLY ORDOÑEZ, LIVIA BUSTOS}

7. Edwaras J. E, Lehrer, R I, et al. Severe Candidal Infec. tions. Ann. Intern. Med. 1978, 89: 91.

8. Marks M I, Marks R N, Brasean M. Yeast colonization in hospitalized and nonhospitalized children. J. Pediatrics. $1975,87: 524-527$.

9. Restrepo $M A$, Quintero $Q M$, Moncada $F L H, C a l l e, V G$ Agentes causales de micosis superficiales en nuestro medio. Antioquia Med. 1970, 20:77.
10. Restrepo A, Moncada L H, Meía M, Correa I, Calle G Candidiasis: La multiplicidad de sus manifestaciones clinicas. Trib. Med. 1973. 47 (8): 15.

11. Klein JJ, Watanakumakorn Ch. Hospital Acquired Fungemia. Am. J. Med. 1979, 69: 51.

12. Silva Hutner $M$, Cooper B H. Yeast of medical importance. Manual of Clinical Microbiology. Lennetre E, Balows A. Hausler W, Truant J (eds) American Society for Microbiology. Washington D.C. 1980 ; pp 562 . 576. 